\title{
A MODIFIED APPROACH TO THE ADOPTIVE IMMUNOTHERAPY OF WALKER-256 CARCINOSARCOMA WITH A COMBINATION OF ACTIVATED MACROPHAGES AND PHOTODYNAMIC THERAPY
}

\author{
VF Dima ${ }^{1}$, V Vasiliu, ${ }^{2}$ D Laky, ${ }^{3}$ N Coman, ${ }^{1}$ MD Ionescu $^{1}$ SV Dima ${ }^{4}$ and Shigeyuki Nakaji ${ }^{5}$ \\ 1: Cantacuzino Institute, 2: Institute of Atomic Physics, 3: Victor Babes Institute, Bucharest, Romania; \\ 4: Centre Medico-Chirurgico S.I.S.Hahnemann, Rome, Italy; \\ and 5: Department of Social Medicine, Hirosaki University School of Medicine, Hirosaki, Aomori, Japan
}

\begin{abstract}
Experiments were performed on five batches of Wistar inbred rats with Walker-256 carcinoma receiving sole (PDT, MAK) or combined therapy (PDT+MAK-A; PDT+MAK-B); the control batch (HBSS) consisted of animals with untreated tumors. The results were as follows: (a) the sole treatment (PDT, MAK) gave survival rates between 37.7 and $47.5 \%$, the "combined" therapy in five doses increased significantly $(70.8 \%)$ the survival rate of tumor bearing rats as well as the rate of complete regression (82.1\%). The cell-mediated immunity test and histopathological and as well as the electron microscopy observation were in full agreement with the results above. Summing up, this results demonstrate that "combined" photodynamic therapy with intra and peritumoral MAK infusion stimulated cell - mediated antitumoral activity, increased survival rates and reduces incidence of Walker-256 carcinoma in rat model.
\end{abstract}

Key words: Photofrin II, He-Ne laser, photodynamic therapy, activated macrophages, multinucleated giant cells

\section{Introduction}

Photodynamic therapy (PDT) is a promising local treatment based on the selective accumulation of a photosensitizer in malignant tissue and the subsequent illumination with laser light of an appropriate wavelength. The laser light excites the molecules of the sensitizer. In an energy transfer process mediated by the excited sensitizer molecules, ground-state tripled oxygen in the tissue is excited to singlet oxygen ${ }^{(1)}$. Singlet oxygen is known as a highly cytotoxic agent, causing membrane dysfunction at many cellular sites $(2,4)$.

In the last ten years, a wide variety of malignancies have been treated by this method and according to the literature, over 3,000 patients world wide have

Addressee for Correspondence:

Shigeyuki Nakaji MD phD,

Department of Social Medicine

Hirosaki University School of Medicine

5 Zaifu-cho, Hirosaki,

036-8562 Japan,

Tel. +81-172-395037, Fax. +81-172-395038,

E-mail.nakaji@cc.hirosaki-u.ac.jp been treated with photodynamic therapy ${ }^{(5,6)}$.

Experimental approaches and clinical investigations have shown that the association of two or more modalities for cancer treatment in animals and humans presents evident advantages and has become a frequently applied treatment $(7,8)$.

In many laboratories, it has been proved that activation of murine macrophages can induce regression of tumors ${ }^{(7)}$ and metastases ${ }^{(8)}$. Similarly, human and murine macrophages differentiated from blood monocytes and activated with interferon have been used in adoptive immunotherapy $(9,10)$. Photodynamic therapy and immunotherapy have been used in various tumor models. However, few studies on the therapeutic effect of the photodynamic therapy associated with activated macrophages have been reported so far ${ }^{(11,12)}$

In the present work, we study morphological modifications which appeared in Walker-256 carcinosarcoma and immunological reactivity of animals after local exposure to photodynamic therapy com-

Manuscript received: August 2006

Accepted for publication: September 2006

Laser Tberapy 15.4: 151-160 


\section{ORIGINAL ARTICLES}

bined with immunotherapy.

\section{Materials and Methods}

\section{Procedures and Experimental Tumor Model}

Walker-256 carcinosarcoma was obtained from the Oncology Institute, Bucharest, Romania and maintained by serial transplantation in inbred Wistar-R8 rats. Tumor suspension $(0.2 \mathrm{ml})$ was subcutaneously injected in the dorsal region of syngeneic animals. Tumor were visible 7 days after transplantation and had a volume between $85-117 \mathrm{~mm}^{3}$.

\section{Hematoporphyrin Derivative}

Rats were intraperitoneally injected with Photofrin II (Photofrin Medical Inc. Cheetkowage, NY.) with a drug dose of $15 \mathrm{mg} / \mathrm{kg}$ body mass. Twenty-four hours later, rats were irradiated with laser.

\section{Laser Therapy}

The light source was a divergent beam from a LG-6 He-Ne laser (632.8 nm, $10 \mathrm{~mW}$ ) whose output was checked with a Spectra-Physics C power-meter.

\section{Monocyte Culture and Activation}

Murine blood monocytes (Mo) were obtained from tumor bearing rats and prepared by the method described by Bartholeyns et $\mathrm{al}^{(9)}$. Briefly, peripheral monocytes were isolated by centrifugation on FicollHypaque (Pharmacia, Upsala, Sweden). These Mo were cultured in RPMI 1640 medium supplemented with penicilin $(100 \mathrm{U} / \mathrm{ml})$, streptomycin $(50 \mu \mathrm{g} / \mathrm{ml})$, oxalacetic $(132 \mu \mathrm{g} / \mathrm{ml})$, insulin $(8 \mu \mathrm{g} / \mathrm{ml})$, glutamine $(2$ $\mathrm{mM})$, pyruvic acid $(2 \mathrm{mM}), 5 \times 10^{-6} \mathrm{M}$ indomethacin, non-essential aminoacids (1 ml Gibco concentrate / $100 \mathrm{ml}$ ) and $10 \%$ fetal calf serum (Gibco, Europe, U.K.) Monocytes were grown on Pyrex bottles $\left(5 \times 10^{6}\right.$ cells $/ \mathrm{ml}$ ) at $37^{\circ} \mathrm{C}$ in a humidified $5 \% \mathrm{CO} 2 / 95 \%$ air incubator. Cells were differentiated into macrophages after 7 days of culture. The effector cells were activated by exposure to $500 \mathrm{U} / \mathrm{ml}$ of recombinant murine interferon-gamma (rMuIFN-gamma) $\left(5 \times 10^{6} \mathrm{U} / \mathrm{mg}\right.$, Genetech Inc. South San Francisco, U.S.A) for 24 hours.

\section{Treatment procedure}

Five different treatments were evaluated in rats with Walker-256 (W256) photodynamic therapy (PDT) in five fractionated, $60 \mathrm{~min}$. each $\left(18 \mathrm{~J} / \mathrm{cm}^{2}\right)$ (batch I); rMuIFN-gamma activated macrophages (MAK-batch II) given peritumorally in five doses $\left(5 \times 10^{6}\right.$ cells/doses/animal) every 3 days; PDT+MAK-A (intratumoral infusion-batch III); PDT+ MAK-B (intra and peri- tumoral infusion batch IV) and HBSS injection (control - batch V). Fraction irradiation of animals in batches I, III and IV was performed at 3 days intervals, followed by MAK infusion $(0.1 \mathrm{ml}$ of suspension was infused into the center of W256 tumor at a speed of $0.1 \mathrm{ml} / \mathrm{h}$ for 3 hours)

The rats were regularly assessed and tumor size was measured (in $\mathrm{mm}^{3}$ ) along three orthogonal diameters (D1; D2; D3) every third day, in first 2 weeks and then weekly untill the treatment ended (60 days). The volume (V) was calculated assuming spheroid geometry using the following formula:

$\mathrm{Vol}=(\pi / 6) \mathrm{D} 1 \mathrm{xD} 2 \mathrm{xD} 3 \mathrm{~mm}^{3}$

The efficacy of activated macrophages (MAK) sole or associated with PDT was estimated by means of the following parameters: (1) in vivo effects of MAK on tumor development; (2) immunological tests; (3) histopathological and (4) electron microscopy observations.

\section{Immunological Tests}

Mitogenic response of spleen cells. The mitogenic activity of spleen cells was assayed by the method described by Csako et al(11). Radioactivity was read in a Beckman-model CPM 100 scintillation counter. Results were calculated from the uptake of ${ }^{3} \mathrm{H}-\mathrm{TdR}$ by the cells and were expressed as mean uptake in cpm/well.

Cytotoxic activity. Cytotoxicity of effector cells was assayed by ${ }^{3} \mathrm{H}$-Uridine method of Nishimura and $\mathrm{al}^{(12)}$. Target cells lysis was calculated by following equation: $\%$ cytotoxicity $=1-(\mathrm{cpm}$ in culture of effector and target cells/cpm culture of target cells alone) x 100

Target cells. The YAC -1 (mouse T cell lymphoma) was used. All cultures were maintained at $37^{\circ} \mathrm{C}$ in a humidified atmosphere of 5\% CO2 in RPMI-1640 medium (Gibco, Grand Island, N.Y.)supplemented with 10\% fetal calf serum

Biodistrubution of labelled macrophages in rat tissues. To determine if there was preferential accumulation of MAK in tumor bearing rat tissues, MAK were labelled with ${ }^{125}$ Iodine. Four days after tumor induction the rat batches (I, III and IV), Guérin tumor-bearing and healthy animals were inoculated intravenously by perfusion with ${ }^{125}$ I-labelled MAK $\left(1.5 \times 10^{8}\right.$ cells - equivalent of $857,962 \mathrm{cpm}$ ). After sacrifice (4 days later), animal tissues were removed, weighed and analyzed for radioactivity in a Beckman gamma counter. The results were expressed as percentage of injected dose per gram of tissue.

Histopathology. Tumors were removed from animals used for immunological tests after three weeks of treatment alone or combined, fixed on buffered formalin, sectioned and stained with hematoxylin-eosin (HE). 


\section{Electron microscopy}

As for histopathological observations, for electron microscopy, treated and untreated tumor tissues (batches I, IV and V), four weeks post-treatment, were fixed in $2.5 \%$ glutaraldenyde in $0.1 \mathrm{M}$ sodium cacodylate buffer, $\mathrm{pH} 7.2$ for $2 \mathrm{hr}$, washed in the same buffered solution, post-fixed in buffered $1 \%$ OsO 4 for $60 \mathrm{~min}$ at $+4^{\circ} \mathrm{C}$ and embedded in Vestopal. Ultrathin sections were cut with Porter-Bloom MT 1 ultramicrotome, mounted on copper grids, stained with uranyl acetate followed by lead citrate and examined at Hitachi-HU 11 electron microscope.

\section{Data analysis}

Data were expressed as arithmetic mean and standard error (S.E.). Significance of differences between groups was calculated by the Kruskall-Willis test.

\section{Results}

\section{Inhibition of Tumor Growth after Local Photodynamic Therapy Associated with Immunotherapy}

Growth results for tumoral volume of all five batches of animals are presented in Figure 1. In control animals (batch V-HBSS injection, no PDT and immunotherapy) tumoral volumes increased approximately 20.3 times, after four weeks.

Growth was only slightly slower in batch I (PDT) and batch II (MAK only). In batch III (animals exposed to local PDT associated with peritumoral perfusion of activated macrophages (MAK), a slower rate of tumoral volume growth was noticed in the first four weeks, followed by a marked decrease in the following weeks and with a cure rate of tumor $53.7 \%$ by the 60 th day mark. In contrast, in batch IV (animals treated with multiple PDT doses associated with intra and peritumoral perfusion of interferon activated macrophages), we noticed a discreet growth of tumoral volume in the first three weeks, followed by $69.8 \%$ cessation of growth.

Sixty days post-transplantation, examination of tumoral volume curves suggested two aspects: (a) local treatment with only PDT or MAK produced lower values of tumoral volume growth; (b) photoexposure of animals to multiple doses associated with activated macrophages led to tumoral volume diminution until complete cure (cure rate: $69.8 \%$ ) and also to an increase in the survival rates (Figs. 1-3); (c) PDT or MAK alone had a smaller influence on tumoral volume and on the animals survival rates in comparison with the combined therapy (Figs. 1, 2)

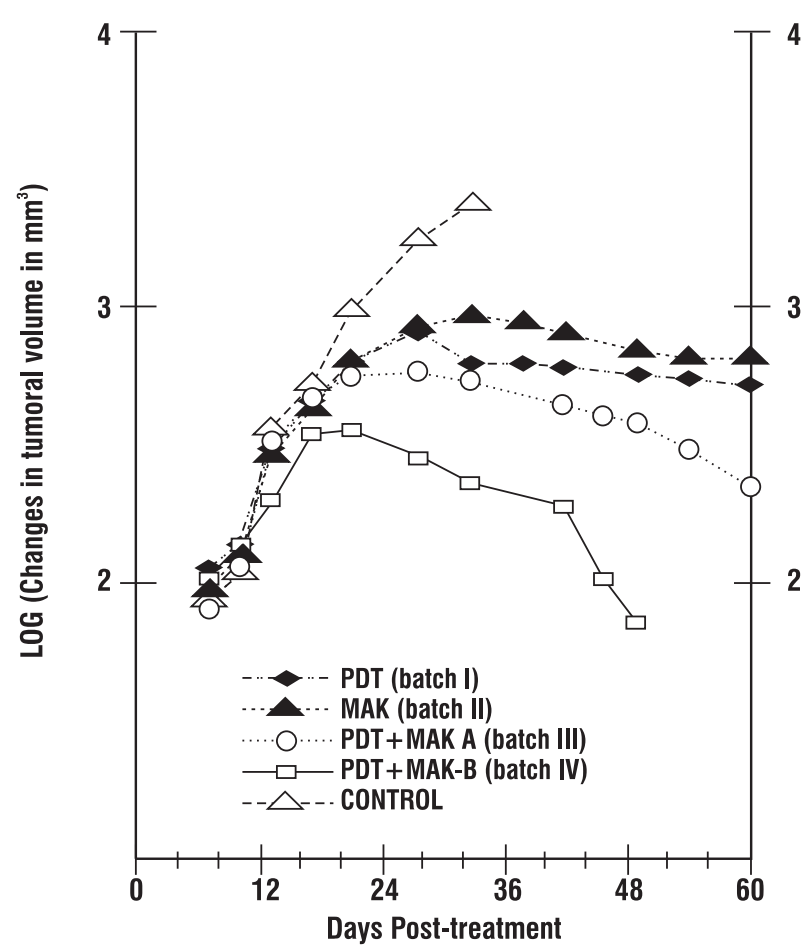

Fig. 1: The change in mean tumor volume in Walker-256 carcinosarcoma injected rats with time after photodynamic therapy combined with immunotherapy. Both tumor-bearing and non tumor-bearing animals are included. 


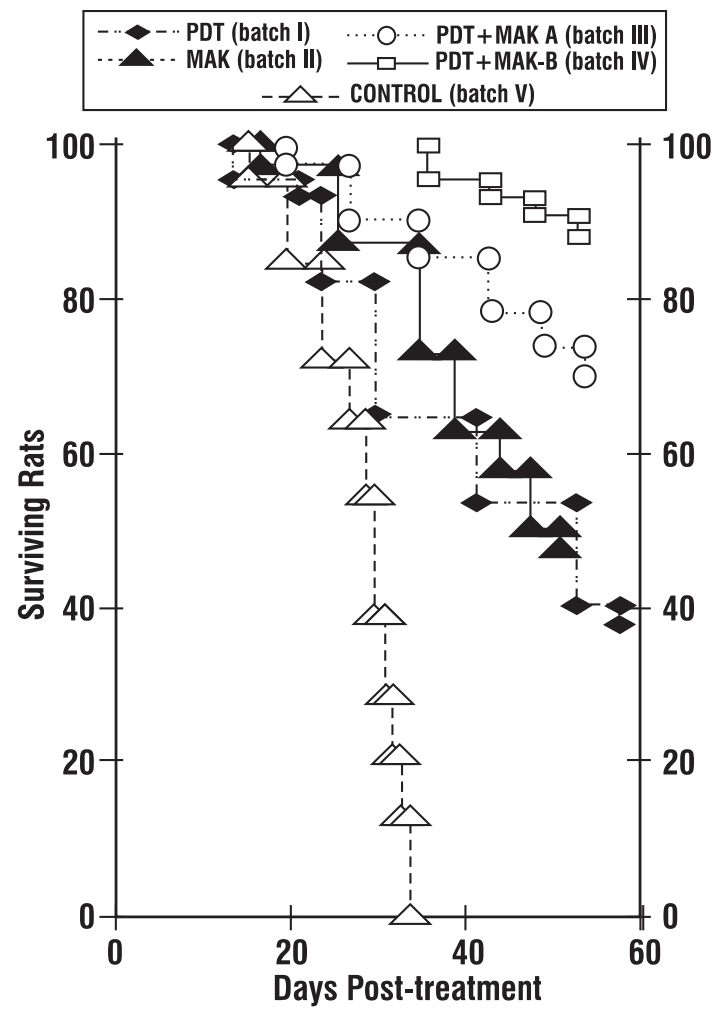

Fig. 2: Therapeutic effect of perfusion with rMulFN-gamma activated macrophages(MAK) combined with photodynamic therapy. Both tumor-bearing and non tumor-bearing animals are included.

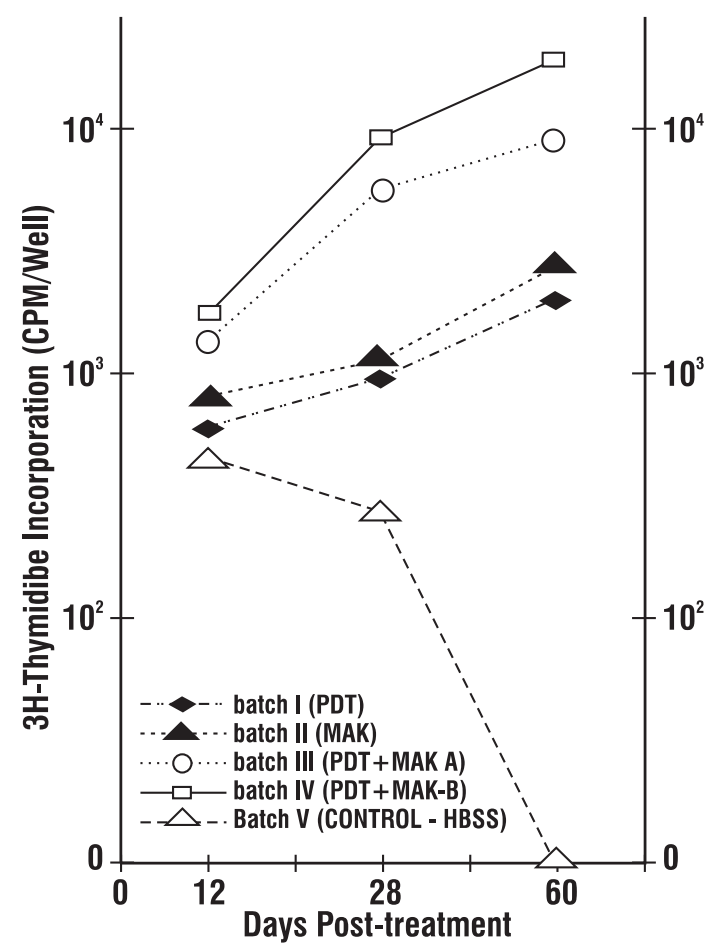

Fig. 3: Mitogenic response of spleen cells cultured with Con A in animals with Walker-256 carcinosarcoma locally treated with PDT and immunotherapy. 
Summing up, all these facts demonstrate the efficacy of local photodynamic therapy with perfusion of interferon activated macrophages in Walker-256 carcinoma.

\section{Mitogenic response of spleen cells}

Cpm mean values after stimulation of lymphocytes with Con A at 12, 28 and 60 days after treatment are present in Figure x.3. Examining it, we can noticed that after 12 days, exposure to multiple doses of combined treatment produced a slower increase of radioactive precursor ${ }^{3} \mathrm{H}-\mathrm{TdR}$ incorporation into Con A stimulated lymphocytes, when splenic cells were cultured at $2.5 \times 10^{5}$ cells/well density; in contrast, after exposure to sole PDT or MAK, we noticed a moderate mitogen response to Con $\mathrm{A}$.

Twenty-eight and sixty days after starting treatment, cpm values found in Con A stimulated lymphocytes were significantly superior to those found after 12 days, especially in batch III, IV, as compared to control batches (I, II, V).

\section{Augmentation of Cytotoxic Activity After Combined Therapy}

The aim of the experiment presented in Table $\mathbf{1}$ was to determine the capacity of combined treatment to stimulate cytotoxic activity of splenic lymphocytes and to lyse target YAC 1 cells 12, 28 and 60 days post-treatment.

Percentage values found for anti-YAC activity of spleen cells from the treated batches were superior to control values (HBSS). Twelve days post-treatment, maximal cytolysis against YAC cells was noticed in splenic lymphocytes from multiple PDT+MAK doses treated animals (batches III and IV). By contrast, sole treatment (PDT+MAK) was not capable to significantly increase cytotoxic activity of effector cells.

Four and eight weeks post-treatment, in all studied batches a higher splenic cytotoxicity was noticed against YAC target cells, in comparison to the values determined at 12 days post-treatment. Anti-YAC cytotoxic activity in batches where adoptive immunotherapy (MAK-A, MAK-B) was associated with PDT was superior to other animal batches (Table 1).

The results suggest two aspects: (1) local combined treatment increases cytotoxic activity against target cells and (2) these activities take place in a dosedependent manner (data not shown). Spontaneous release of the isotope from target cells was less than $10 \%$ during the test.

\section{Biodistribution of Labelled Macrophages in Rat Tissues.}

The tumor bearing animals exposed to photodynamic treatment combined with immunotherapy in multiple doses and intravenously inoculated with ${ }^{125}$ I-labelled macrophages $\left(5 \times 10^{8}\right.$ cells $/ \mathrm{ml}$ equivalent to 857.962 $\mathrm{cpm} / \mathrm{ml}$ ) and sacrificed four days after injection, showed the highest label in liver (form 23.9 at 27.2\%) and lung ( 5.5 at $7.9 \%$ ) followed by label in spleen. The total radioactive values found in the studied tissues of animals with treated and untreated Walker-tumors, Guérin tumor tissues and healthy animals varied between 18.6 and $51.1 \%$. The remaining radioactivity of the values was retained in other tissues and in animal carcass which was not measured.

After intratumoral perfusion of labelled macrophages, the radioactivity values found at tumor periphery and center varied between 62.8 and $72.2 \%$ in batches III and IV, 51.3\% in untreated Walker-256 tumor and only $26.9 \%$ in Guérin tumor cells. Infused labelled-MAK intratumorally remained in the tumor mass with a slow redistribution in the body. The representative experiment is shown in Table 2.

\section{Histopathological Examination}

Morphological modifications occurring in tested and control animals with Walker-256 carcinoma were stud-

Table 1: Cytotoxicity assays using splenic effector cells from Walker-256 carcinosarcoma-injected rats.

\begin{tabular}{llccc}
\hline \multirow{2}{*}{ Treatment batch \& method } & \multicolumn{2}{c}{ Percentage of cytotoxicity against target YAC-1 cells } \\
\cline { 2 - 5 } & PDT & $\begin{array}{c}\text { 12 days after } \\
\text { treatment }\end{array}$ & $\begin{array}{c}\text { 28 days after } \\
\text { treatment }\end{array}$ & $\begin{array}{c}\text { 60 days after treat - } \\
\text { ment }\end{array}$ \\
\hline I & MAK & $20.7 \pm 1.49$ & $23.7 \pm 0.68$ & $29.5 \pm 1.47$ \\
\hline II & PDT+MAK-A & $22.5 \pm 0.72$ & $23.9 \pm 2.04$ & $31.8 \pm 1.42$ \\
\hline III & PDT+MAK-B & $25.1 \pm 2.08$ & $28.6 \pm 2.92$ & $35.7 \pm 2.39$ \\
\hline IV & CONTROL $(H B S S)$ & $27.4 \pm 0.79$ & $33.8 \pm 1.72$ & $41.5 \pm 3.26$ \\
\hline $\mathrm{V}$ & $18.5 \pm 2.63$ & $19.2 \pm 1.86$ & - \\
\hline
\end{tabular}




\section{ORIGINAL ARTICLES}

Table 2: Biodistribution of labeled macrophages in rat tissues.

\begin{tabular}{lccccc}
\hline \multirow{2}{*}{ Tissue } & \multicolumn{5}{c}{ 125I-labelled uptake (\%/g of tissue) } \\
\cline { 2 - 4 } & Walker-256 & Walker-256 + Macrophages & \multirow{2}{*}{ Guérin } & \multirow{2}{*}{ Control $^{\ddagger}$} \\
\cline { 2 - 4 } & $21.5(1.93)$ & $23.9(3.10)$ & $27.2(2.85)$ & $19.7(2.70)$ & 5.4 \\
\hline Liver & $4.9(0.63)$ & $5.5(0.83)$ & $7.9(0.59)$ & $6.2(0.47)$ & 6.8 \\
\hline Lung & $3.5(0.52)$ & $2.9(0.95)$ & $3.7(1.05)$ & $2.8(0.59)$ & 3.1 \\
\hline Spleen & $1.6(22.40)$ & $2.7(28.40)$ & $3.8(32.60)$ & $1.3(9.75)$ & - \\
\hline Tumor center & $2.4(25.20)$ & $5.6(29.0)$ & $6.1(34.90)$ & $1.7(12.70)$ & - \\
\hline Tumor periphery & $2.7(0.60)$ & $2.1(0.55)$ & $2.4(071)$ & $2.9 .(0.69)$ & 3.3 \\
\hline Blood & $38.6(51.28)$ & $42.7(62.8)$ & $51.1(72.7)$ & $34.6(26.9)$ & 18.6 \\
\hline Total & & &
\end{tabular}

* Intravenously or intratumorally (in parentheses) perfusion of ${ }^{125}$ I-labelled macrophages I A:PDT+MAK-A (batch III); B: PDT+ MAK-B (batchIV).

$¥$ Control: Healthy animals

ied three weeks post-treatment. The following could be noticed: typical Walker-256 tumor aspect with small cells, oval or rounded, presenting nuclei with rich chromatin; large cells with multiple nuclei, presenting characteristic atypia for tumor cells leading to the conclusion that the tumor was a weakly differentiated tumor of sarcomatous type.

In animals exposed to PDT (batch I) tumor proliferation is more restricted; at various levels we noticed necroses zones and vascular changes of obliterating endovascularitis type. In animals from batch II, intratumorally injected with MAK, an extension of necroses regions in tumoral mass, edema, macrophages and leukocytic infiltration zones can be noticed. In animals from batch III exposed to PDT+ MAK-A: histological variations could be seen from one zone to another with alternative tumor cells with vacuolar and dystrophic lesions; numerous neutrophile polymorphonuclears, lymphocytes and macrophages elements; vasodilatation and edema were observed. In animals from batch IV, exposed to PDT associated with activated macrophages (PDT+ MAK-B) intra and peritumoral perfusion, we noticed large hemorrhagic regions, marked vasodilatation, extended necroses with few isolated tumor cells; macrophages infiltration (some of them polynucleated) in the tumor center and periphery are in small or large groups. No tumoral proliferation was detected.

\section{Electron Microscopy of the Walker-256 Carcinosarcoma}

On electron micrographs of typical Walker-256 tumor cells we noticed the following: each tumor cell had a single indented nucleus containing peripheral clumped heterochromatin (Fig.4). The nuclear indentation varied from shallow "nuclear hoops" to deeper finger-like portions of cytoplasm. Nuclear chromatin finally dispersed and nucleoli were not usual in their appearance.

The cytoplasm of tumor cells contained relatively few organelles: swelling mitochondria round or ovoid; cristae were not abundant and some empty mitochondria were evident (Fig. 4). The cytoplasm was packed with free ribosomes and polyribosomes, whereas the rough endoplasmic reticulum was poorly developed. Some cells contained large lipid droplets within their cytoplasm. The surface of tumoral cells had folds and short filopods. The presence of pseudopodal cytoplasmic extension of the tumor cells into the adjacent cells seems to be indicative of ameboid motility and invasive nature of some tumors.

\section{Fine Structure of Tumor Cells Exposed to Photodynamic Therapy}

Walker tumor cells sensitized with Photofrin II and exposed to He-Ne laser irradiation $\left(18 \mathrm{~J} / \mathrm{cm}^{2}\right)$ showed some differences in nuclei and cytoplasm between the control tumoral cells and those treated by PDT.

Dense chromatin can be seen within nucleus; in cytoplasm, Golgi complex in some cells is well represented; swollen mitochondria with tendency of the decrease in number; on the other hand the cytoplasm appeared rich in small dense particles which appeared in small clusters; in some cells we noticed the presence of cells in mitoses (Fig. 5) 


\section{Ultrastructural Changes of Walker Carcinoma Cells Exposed to Local Associated Therapy}

Examination on electron micrographs of Walker-256 tumor cells sensitized with Photofrin II and exposed to He-Ne laser irradiation $\left(18 \mathrm{~J} / \mathrm{cm}^{2}\right)$ combined with peri and intratumorally infusion with rMuIFN-gamma activated macrophages (MAK) in five doses showed strong changes in the nuclear and cytoplasmic fine structure. A. The following nuclear lesions were noticed on electron micrographs: (1) the nuclear heterochromatin was scattered in fine or larger packs in the nuclear mass (Fig.6); (2) varying number of nuclear indentation were observed; nucleus was reduced in volume and frequently homogenization and lysis of nuclear chromatin were noticed four weeks post-treatment (Figs.69); nucleoli disappeared. Homogenization of nuclear chromatin may results from depolymerization of deoxyribonucleic acid. B. Ultrafine changes noticed in cytoplasm of tumor cells were characterized by: (a) compartmentalisation and vacuolisation of cytoplasm; (b) rough endoplasmic reticulum poorly developed; (c) progressive degradation of cell organelles and sometimes loss of identity (Figs. 6-9); (d) the cytoplasm was depleted or ribosomes and few vesicles and dense bodies were present (Fig. 9); (e) lipid droplets of different sizes were distributed within cytoplasm (Fig. 9); (f) the cytoplasm filopods nearly disappeared at the contact zone with MAK cells, as wel as the plasma membrane integrity appeared to be lost at several points and complete membrane lysis was observed (Figs. 9); In some cells we noticed in the cytoplasm giant phagosomes (especially in Fig. 8) with amorphous material (tumoral) inside (Figs. 7, 8).

A careful examination of micrographs to proceed from animals treated by several doses of association therapy (PDT+MAK-B) we noticed the presence of the multinucleated giant cells (Figs. 6-8). The number of nuclei in the multinucleated giant cells varied depending on the number of peri and intratumoral perfusion with MAK cells (Data not shown).

\section{Discussion}

In the present study, we noticed that association of photodynamic treatment with immunotherapy significantly reduced mortality, volume and tumoral incidence in inbred Wistar rats with Walker-256 carcinosarcoma. In the present paper, as in the previous one ${ }^{(13)}$ we noticed that association of photodynamic treatment with immunotherapy significantly reduced mortality, volume and tumoral incidence in inbred Wistar rats with Walker-256 carcinosarcoma. Tumoricidal incidence decrease both as progression and regression, was assigned to exposure to photodynamic therapy but also to rMuIFN-gamma activated macrophages (MAK) association, increasing cell-mediated immune response. The electron microscopy observation sug-

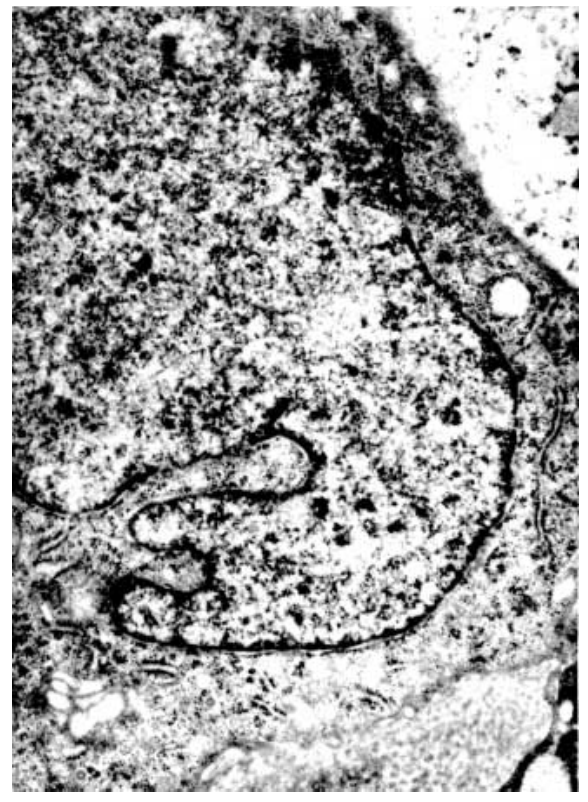

Fig. 4: Electron micrograph of Walker-256 tumor cells. Uranyl acetate and lead citrate staining. Magnification, x 13,500.

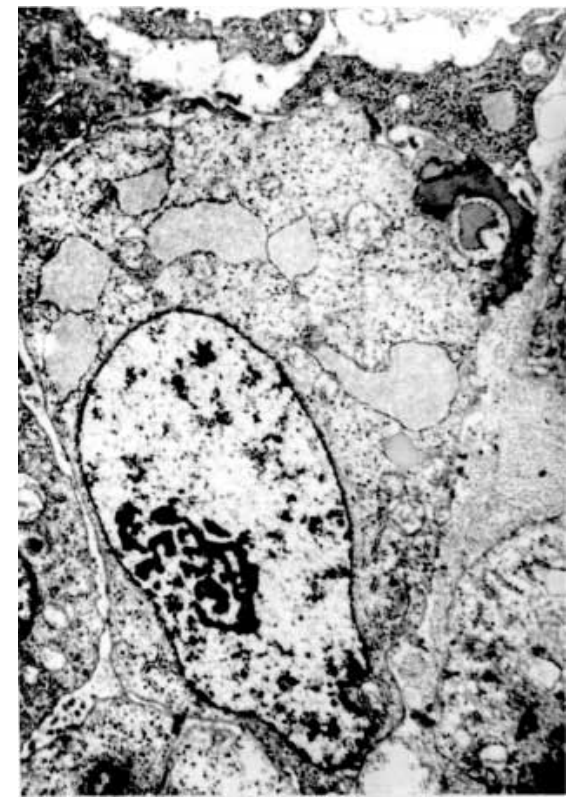

Fig. 5: Electron micrograph of tumor cells after photodynamic therapy. Note: tumor cell in mitosis. Magnification, x 4,250. 


\section{ORIGINAL ARTICLES}

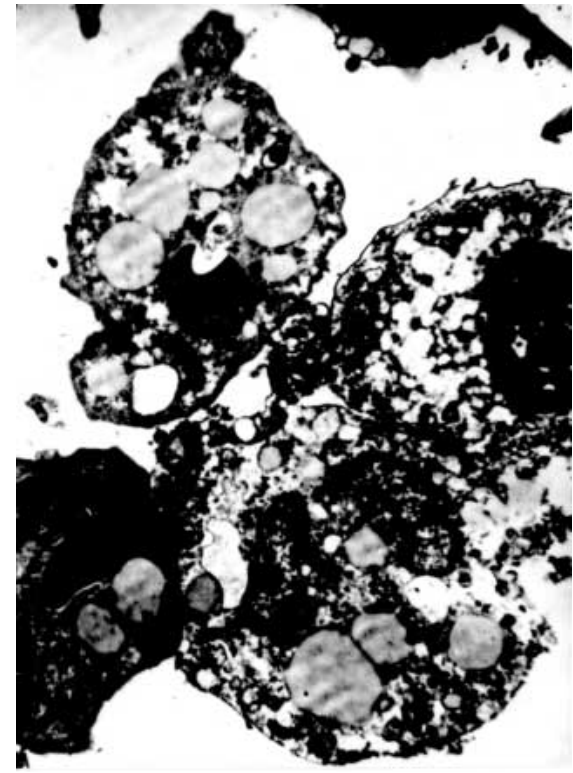

Fig. 6: Electron micrograph of tumor cells treated by five doses of combined therapy. Note: strong alterations of nuclear and cytoplasmic structures and two macrophages attached to them. Magnification, $x$ 4,250 .

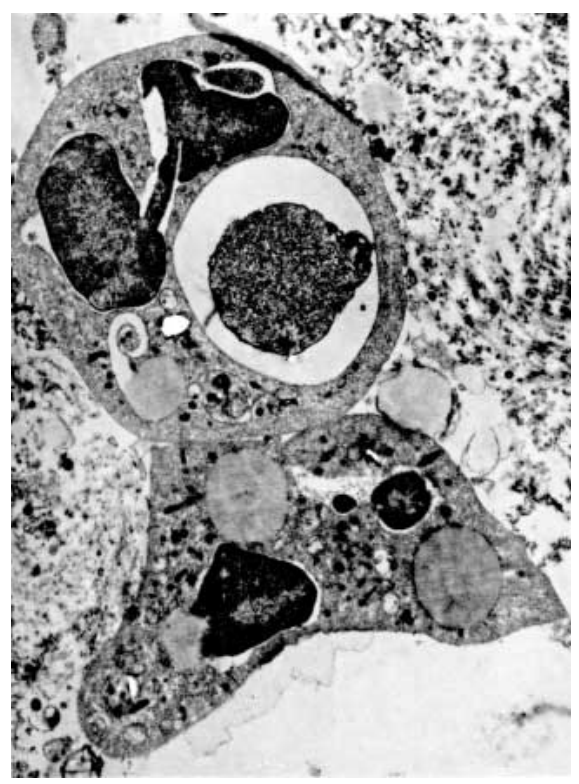

Fig. 8: Electron micrograph of two multinucleated giant cells. Note: each cell has two nuclei of different sizes; in the cytoplasm of the right cell one be see a giant phagosome with ingested amorphous material; around the giant cells, altered tumoral fragments can be seen. Magnification, x 4,250.

gested a good correlation between the results obtained by above methods and fine structure of Walker-256 carcinoma after local associated therapy.

One of the most important questions about MAK

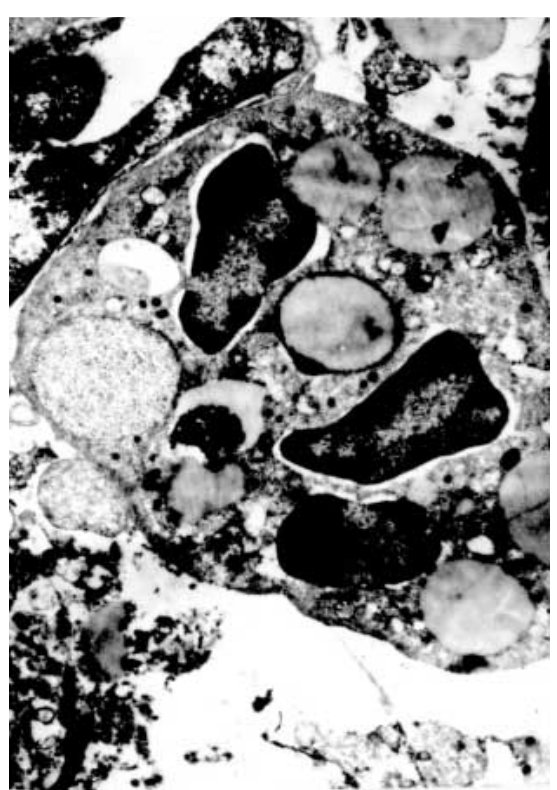

Fig. 7: Fine section of multinucleated giant cell (with 3 nuclei phagocytic vacuole with amorphous material inside) in contact with tumoral fragments; in the left down corner of picture a nuclear tumoral fragment can be seen. Magnification, x 7,400.

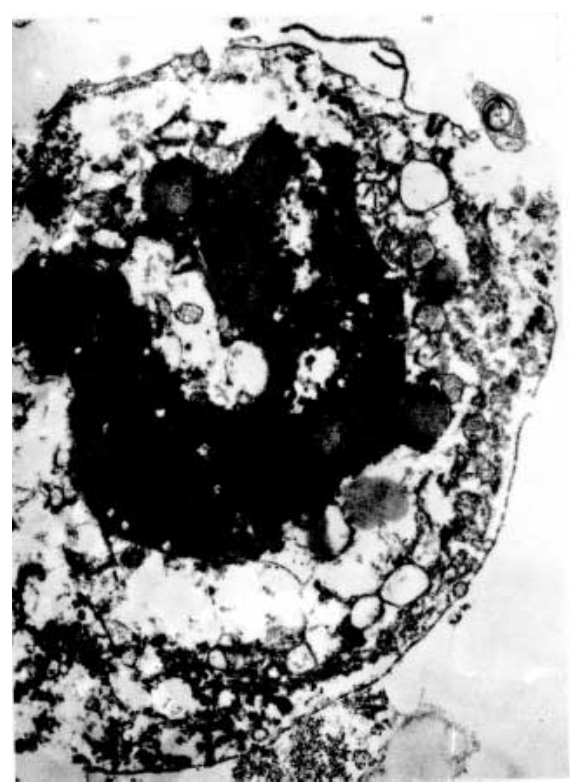

Fig. 9: Electron micrograph of fine section of tumor cells 4 weeks post-associated treatment. Note: homogenization and lysis of tumor nuclear chromatin, disorganization of cytoplasm, degradation of cell organelles and cytoplasmic membrane lysis. Magnification, x 12,000.

therapy is what are the tissue and organ affinities of MAK. In our studies we carried out the biodistribution of ${ }^{125}$ I-labelled MAK in untreated and treated rats with Walker-256 carcinoma. The results pointed out a pre- 
dominant accumulation of ${ }^{125}$ I-labelled MAK in liver, kidney and spleen and lower amounts in other organs and tissues 4 days post-intravenous perfusion.

After intratumorally perfusion of ${ }^{125}$ I-labelled MAK, the radioactive values found at tumor periphery and center were highly significant in batches exposed to combined therapy. Infused labelled-MAK intratumorally remained in the tumor mass with a slow redistribution in the body. These observations suggest a selective localisation of labelled MAK in Walker-256 carcinosarcoma. Similar investigations for preferential localisation of labelled immunocompetent cells were reported also by other researchers in animals and human adoptive immunotherapy with activated macrophages $^{(12,19,20)}$.

Higher values observed in animal tissues infused with ${ }^{125}$ I-labelled MAK could be explained by two factors: (1) animals were sacrificed four days after MAK infusion and (2) association of PDT to immunotherapy in multiple doses, the last one increased significantly the susceptibility of tumor cells to activated macrophages and consecutively a better localisation of labelled MAK into tumor tissues was observed.

In connection with the presence of multinucleated giant cells on electron micrographs to proceed from animals which received combined therapy, we suggest that the macrophage fusion could be initiated by some cytokines. Between several cytokines produced locally by MAK, three (IL-6, IFN-gamma, and GM-CSM) emerged as candidate for macrophage fusion factor (MFF) production. The last one GM-CSF induced not only growth but also differentiation of monocyte to macrophages $^{(12,21,22)}$.

These studies raise other two questions. First, which are the main PDT target on tumor cells and which are the mechanism of antitumoral effects of activated macrophages?

In connection with the first question, the targets include: (a) the membrane of the cell, nucleus, mitochondria, lysosomes, Golgi apparatus and endoplasmic reticulum as well as the endothelium of the microvascular system $^{(4)}$; (b) mitochondria are the primary target of PDT ${ }^{(5)}$ and this is in agreement with the subcellular distribution of the dye as well as their functional activities (inhibition of respiration, oxidative phosphorylation and calcium uptake(6); (c) DNA degeneration mediated by endonucleases and characterized by apoptosis; the last process involves the participation of $\mathrm{Ca}^{2+}$ through activation of $\mathrm{Ca}^{2+}-$ dependent endonucleases ${ }^{(23-25)}$

Besides PDT mechanisms, we could add the following antitumoral effects of activated macrophages: (i) cytotoxicity and cytostatis mediated by monokines in membrane associated or soluble forms (IFN, TNF, IL-1) $(26,27)$; ii) killing and ingestion of tumor cells by phagocytosis and probably apoptosis $(24,25)$; iii) cytokine "cascade" is responsible for immune response amplification, involving various kinds of soluble factors produced by a variety of immuno-competent and immuno-associated cells ${ }^{(28)}$.

Summing up, this work demonstrates that "combined" photodynamic therapy with MAK stimulated cell-mediated antitumoral activity, increased survival rates and reduced incidence of carcinosarcoma in a rat model.

\section{References}

1: Kimel, S., Tromberg, J.P., Roberts G.W. and Berns, M.V. (1989) Singlet oxygen generation of porphyrins, chlorides and phtalocyanines. Photochemistry and Photobiology, 50, 175-183.

2: Dougherty, J.T., Photosensitization: therapy and detection of malignant tumors. (1987) Photochemistry and Photobiology., Vol. 45, pp. 879-889.

3: Ben-Hur, E., Carmichael, S., Riesz, P., Rosenthal, I. (1985) Photochemical generation of superoxide radical and the cytotoxicity of phtalocyanines. International Radiation Biology Related Studies Physical, Chemistry and Medicine, 48, 837-846.

4: Jori, G., Reddi, E., Cozzani I. and Tomio, L. (1986) Controlled targeting of different subcellular sites by porphyrins tumor bearing mice, British Journal of Cancer, 53, 615-621,.

5: Sharkey, S.M., Wilson, C., Moorehead R. and Singh, G. (1993) Mitochondrial alterations in photodynamic therapy - resistant cells. Cancer Research, 53, 4994-4999.

6: Shulok, M.H.Wade and Lin, C.W. (1990) Subcellular localization or hematoporphyrin derivative in bladder tumor cells in culture. Photochemistry and Photobiology, 51, 451-457.

7: Kato, H., Horai, T., Furuse, K., Fukuoka, M., Suzuka, S., Hiki, Y., Ioto, Y., Nimura, S., Tenjin, Y., Hiszumi, H., and Hayata, Y. (1993) Photodynamic Therapy for Cancers: A clinical trial of Porfimer sodium in Japan Journal of Cancer Research 84, 1209-1214.

8: Dima, F.V., Vasiliu, V., Laky, D., Ionescu, M.D. and Dima, V.S. (1993) Treatment of rat Walker-256 carcinosarcoma with photodynamic therapy and endotoxin irradiated with high enrgy electrons. Progress in Biomedical Optics. Proceedings of Photodynamic Therapy of Cancer SPIE 2078, 547557, USA. 
9: Dima, V.F., Vasiliu, V., Laky, D., Dima, S.V., Popa, A. and Stirbet, M. (1990) Response of murine mammary adenocarcinoma to photodynamic therapy and immunotherapy. Laser Therapy, Vol.2, pp. 153-160.

10: Spaeth, D., Conroy, T., Krakovwski, I., Geoffrois, L., Luperosi, E., Rios, M., Weber, B. Cisplatium and long term continous infusion ofs Fluorouracyl in the treatment of advanced breast cancer: Advanced breast cancer-a retrospective study of 77 patients, Bulletin du Cancer, Vol.80, pp.351-356, 1993

11: Dougherty, T.J. (1986). Photosensitizer of malignant tumor. Seminars of Surgical Oncology 2, 2437.

12: M.Chokri, M.Freudenberg, C.Galanos, P.Poindron and J.Bartholeyns, (1989) "Antitumoral effects of lipopolysaccharides, tumor necrosis factor, interferon and activated macrophages: Synergism and tissue distribution", Anticancer Research, 9,.11851190 ,

13: Bartholeyns J. and Lopez, M. 1 (994) Immune control of neoplasia by adoptive transfer of macrophages: Potentiality for antigen presentation and gene transfer, Anticancer Research, 14, 26732676.

14: .Andreesen, R., Hennemann, B. (1991) Adoptive immunotherapy with autologous macrophages : Current statusn and future perspectives, Pathobiology, 51, 259-263.

15: Dima, F.V., Vasiliu, V., Laky, D. and Ionescu, M.D. (1992). Adoptive immunotherapy of Walker-256 carcinosarcoma with activated macrophages by C. parvum, interferon and photodynamic therapy. Photobiology: the Macrophages, p.6. European Conference on Basic and Clinical Aspects of Macrophage Biology, Regensburg, Germany.

16: Bartholeyns, J.B., Lopez M. and Andreessen, R. (1991) Adoptive Immunotherapy of Solid Tumors with Activated Macrophages: Experimental and Clinic Results, Anticancer Research, 11, 1201-1204.

17: Csako, G., Suba, E.A., Tsai C.M. and Elin R.J. (1986) Relation of structure to function for the USA refercence standard endotoxin after exposure to ${ }^{60} \mathrm{Co}$ radiation. Journal of Infectious Diseases, 153: 98-108.

18: Nishimura, T., Togashi, Y., Goto, M., Yagi, H., Uchiyama Y. and Hashimoto, Y. (1986) Augmentation of the therapeutic effciency of adoptive tumor immunotherapy by in vivo administration of slowly released recombinat interleukin 2 . Cancer Immunology and Immunotherapy, 2112 18

19: Lotze, M. T., Line, M.R., Martinen,D.J., Rosenberg,
S.A. (1980). The in vivo distribution of autologous human and murine lymphoid cells growth factor (TCGF): Implication for the adoptive immunotherapy of tumors. Immunotherapy of tumors. Immunology 125, 1487-1493.

20: Stevenson H.C., Keenan, A.M., Woodhouse, C., Ottow, R.T., Miller, P., Steller, E.P., Foon, K.A., Abrams, P.G., Berman, J., Larson, S.M. and Sugarbaker, P.H. (1987). Fate of Gamma Interferon activated killer blood monocytes adoptively transferred into the abdominal cavity of patients with peritoneal carcinoma. Cancer Research 15, 61006103.

21: Abe, E., Ishimi, Y.S., Jin, H.C., Hong, H.M., Sato, T. and Suda, T. (1991). Granulocyte-macrophage colony-stimulating factor is a major macrophage fusion factor present in conditioned medium of concanavalin A-stimulated spleen cell cultures. Journal of Immunology 147, 1810-1815.

22: Honma, T. and Hamasaki, T. (1996). Ultrastructure of multinucleated giant cell apoptosis in foreignbody granuloma. Virchows Archives 428, 165-176.

23: McConkey, P., Hartzell, P., Jondal M. and Orrenius, S. (1989) Inhibition of DNA fragmentation in thymocytes and isolated thymocyte nuclei by agents that stimulate protein kinase C. Journal of Biological Chemistry, 264, 13339-13402.

24: Zhou, C., Shunji, C., Jinsheng, D., Junlin, L., Jori G.and Milanesi. C. 1996 "Apoptosis of mouse MS-2 fibrosarcoma cells induced by photodynamic therapy with Zn (II) - phthalocyanine," Journal of Photochemistry and Photobiology B:Biology, 33, 219-223.

25: Hickman, J.A., (1996) Apoptosis chemotherapy resistance, European Journal of Cancer, 12A, 921926.

26: Funk, J.O., Kruse A. and Kirchner, H. (1992) Cytokine production after Helium-Neon laser irradiation in cultures of human peripheral blood mononuclear cells. Journal of Photochemistry and Photobiology B:Biology, 16 347-355.

27: Jori, G. (1994) Response of tumor tissues to photodynamic therapy, in Photodynamic Therapy of Cancer., Julio Jori, Johan Moan, Willen M.Star, Editors, Proc. SPIE 2078, 286-292.

28: Boccoli, G., Masciulli, R., Ruggeri, E.M., Carlini, P., Gianella, G., Montesoro, E., Mastroberardino, G., Isacchi, G., Testa, U., Calabresi F. and Peschle, C. (1990) Adoptive immunotherapy of human cancer: The cytokine cascade and monocyte activation following high-dose interleukin 2 bolus treatment. Cancer Res., 50, 5795-5800. 